\title{
Correction to: Proactive Recruitment of Older African-Americans for Alzheimer's Research with Brain Donation: a Cohort Case Study of Success
}

\author{
Charlene J. Gamboa ${ }^{1}$. Wrenetha A. Julion ${ }^{2}$ \\ Published online: 8 July 2020 \\ (C) W. Montague Cobb-NMA Health Institute 2020
}

The Acknowledgement section is missing from this article as published.

Here are the missing Acknowledgements:

Acknowledgements The authors deeply appreciate the selfless participation of the hundreds of older African-American research participants of the Minority Aging Research Study (MARS). This article could not be possible without the support of MARS' Principal Investigator, Dr. Lisa L. Barnes and her unwavering caring protection of the participants of MARS. We also gratefully acknowledge the Rush Alzheimer's Disease Center (RADC) Education and Outreach team, (Karen Graham, Judy Phillips and Mary Futrell); MARS Brain Donation Team of research assistants (Shayla Calloway, Tequilla Lidell, Elisha Nance, Donald Murry and a great deal of other research assistants); Phlebotomists (Charles Dombroski and Joycine Richardson) and our nurses (Emmanuel Anderson, Irene Condon, and a host of additional nurses). The RADC Donation Coordinators, Traci Colvin and Theresa Jenkins; RADC Pathology team; MARS specific Medical doctors (Neelum Aggarwal, Raj Shah, Debra Fleischman, David Bennett, and a host of other RADC doctors) for their willingness to make the necessary emotional investment into MARS participants. This is not a complete acknowledgement of the countless community organizations, churches, social clubs and social services agencies as well as others who have greatly contributed to the success of the Minority Aging Research Study.

Publisher's Note Springer Nature remains neutral with regard to jurisdictional claims in published maps and institutional affiliations.

The online version of the original article can be found at https://doi.org/ 10.1007/s40615-020-00803-w

Charlene J. Gamboa

Charlene_Gamboa@rush.edu

1 Rush Alzheimer's Disease Center, Rush University Medical Center, 1750 West Harrison Street, Suite 1000, Chicago, IL 60612, USA

2 College of Nursing, Rush University, Chicago, IL, USA 